\title{
Age Inclusive Compassion-Focused Therapy: a Pilot Group Evaluation
}

\author{
Anna Altavilla ${ }^{1}$ (D) Anna Strudwick ${ }^{2}$
}

Accepted: 7 January 2022 / Published online: 18 January 2022

(C) The Author(s) 2022

\begin{abstract}
This study aimed to evaluate and provide recommendations to improve the effectiveness of an age inclusive compassion-focused therapy (CFT) group in secondary mental health services for participants experiencing a range of mental health difficulties. Of particular interest was the acceptability and impact of having a wide range of ages in such a group. The study employed a mixed method design. Validated self-report questionnaires were administered before and after the group intervention, and qualitative semi-structured interviews were conducted with six group participants. There was a significant increase in ratings on the Self-Compassion Scale (SCS) and Mindful Attention Awareness Scale (MAAS), a significant decrease in the depression subscale within the Depression and Anxiety Stress Scale (DASS) and a significant reduction in the risk subscale of the Clinical Outcome in Routine Evaluation (CORE). No significant differences were found on the overall scores and other subscales of the CORE and the DASS. Thematic analysis of the qualitative data identified four main themes: "Connection with others", "Experience of a diverse age range", "Group as a secure space" and "New strategies and tools". This study provides preliminary evidence that an age inclusive CFT group is well received and has a beneficial impact for participants, with particular positivity gained through compassionately connecting with others. The range of ages was appreciated and appeared to have therapeutic benefits, although awareness of differing age-related needs is important. Limitations, recommendations for improvement and future research are discussed.
\end{abstract}

Keywords Compassion-focused therapy · Age inclusive · Older adults · Group · Trans-diagnostic $\cdot$ Secondary mental health

Anna Altavilla

a.altavilla@nhs.net

1 IAPT Wiltshire Service, Green Lane Hospital, Lodge 3, Devizes SN10 5DS, UK

2 University of Bath, Claverton Down, Bath BA2 7AY, England 
Shame and self-criticism underpin a number of psychological difficulties and can be viewed as trans-diagnostic in that they contribute to accentuating and maintaining a range of mental health problems (Gilbert, 2018). Additionally, high levels of self-criticism can limit the effectiveness of therapy (Gilbert and Irons, 2005). To address these issues, there has been an increased focus on cultivating compassion in psychotherapy research. Compassion can be defined as, "the sensitivity to suffering in self and others, with a commitment to try to alleviate and prevent it" (Gilbert, 2014, p14). A substantial amount of research has documented the beneficial effects of compassion on well-being (Crocker and Canevello, 2012; Macbeth and Gumley, 2012; Rockliff et al. 2008).

There are a range of compassion-based psychological interventions with empirical support. A recent meta-analysis examining 21 randomised controlled trials of compassion-based psychological interventions over the last 12 years found significant between group differences on self-report measures of compassion, self-compassion, mindfulness, anxiety, depression, psychological distress and well-being (Kirby et al. 2017). The most evaluated of these is compassion-focused therapy (CFT), developed by Paul Gilbert. CFT draws its theoretical underpinnings from evolutionary psychology, attachment theory, neuroscience and social psychology (Gilbert, 2009).

The CFT model postulates that accessing affiliative emotions is key in regulating threat-based emotions (Gilbert, 2009). People who have experienced difficult early life experiences, including trauma or neglect, may be more attuned to threat-based emotions than positive, affiliative emotions, thus increasing their susceptibility to psychological difficulties. Three types of affect regulation systems are described in CFT (Gilbert, 2009). The threat-focused system focuses on self-protection and safety seeking and produces emotions such as anxiety, anger and disgust. The incentive and resource-focused system motivates, guides and encourages us and produces excitement, drive and vitality. Finally, the affiliative system focuses on soothing, safeness and kindness and is associated with contented and connected emotions. The aim of CFT is to enhance the affiliative system which will in turn improve regulation of the threat-focused system, resulting in improved psychological well-being. CFT interventions involve psychoeducation of the theory of the model, including helping people to formulate and make sense of their difficulties within this model's framework and compassionate mind training (CMT) refers to the specific interventions implemented to increase the affiliative system (Gilbert, 2009). Interventions can include "soothing rhythm breathing", cultivating compassionate imagery, compassionate writing in addition to many other compassionate ways of thinking and behaving (Gilbert, 2009).

CFT is a relatively new therapeutic approach with a growing evidence base. Craig et al. (2020) conducted a systematic review of CFT interventions which included 29 studies and found that it is likely to be more effective than no treatment in clinical populations and is especially effective when delivered in a group format for at least 12 hours. CFT shows benefits across a wide range of complex presentations and is particularly helpful for people experiencing high levels of shame and self-criticism.

However, the reviewers report that before it can be considered evidence-based, a higher standard of research studies is required. Within this review, 22 of the studies 
were CFT groups; the majority of which were clinical participants experiencing a wide range of mental health problems including psychosis, depression, personality disorder and eating disorders. A minority of the groups examined other populations including people with a learning disability (Clapton et al. 2018), dementia (Collins et al. 2018) and acquired brain injury (Ashworth et al. 2015). Overall, these groups had a positive impact, including significant improvements on a variety of outcome measures including an increase in self-compassion and mindfulness and a decrease in depression, anxiety and shame (e.g., Bartels-Velthuis et al. 2016; Feliu-Soler et al. 2014; Judge et al. 2012).

The CFT groups in mental health populations in Craig et al.'s (2020) review are primarily aimed at working age adults, with a collective age range from 18 to 69 years, and the majority of groups having a mean age of participants in their $20 \mathrm{~s}, 30 \mathrm{~s}$ and 40 s (e.g., Braehler et al. 2013; Duarte and Pinto-Gouveia, 2017; Judge et al. 2012; McManus et al. 2018; Noorbala et al. 2013). Whilst a CFT group for people with a diagnosis of dementia is included (Collins et al. 2018), the CFT groups in mental health settings did not include a focus on people from an older adult population.

\section{Older Adults and Compassion}

The limited evidence for CFT with older adults is particularly significant given that people are living longer than ever which is often accompanied by numerous physical, cognitive and social changes (Allen et al. 2012). Older adults have increased likelihood of experiencing multiple losses, dependency on others and reduced ability to engage in activities which can negatively impact psychological well-being and quality of life. In those who are vulnerable, the impact of these additional stressors may increase the likelihood of self-criticism and shame (Mirowsky and Ross, 1992); therefore, the ability to cultivate compassion is important in this age group.

Although the majority of compassion literature has focused on working age adults, preliminary evidence suggests that self-compassion may have significant benefits for older adults. For example, a systematic review by Brown and Ryan, (2003) found that self-compassion was associated with reduced depression and anxiety and increased levels of hedonic and eudaimonic well-being. Studies within this review included Allen et al. (2012), who found that older adults with poorer physical health who were higher in self-compassion reported greater subjective well-being compared to those with lower self-compassion. Further, Phillips and Ferguson, (2012) found that self-compassion was positively associated with meaning in life, ego integrity and positive affect and negatively associated with negative affect. These studies suggest that a compassion focused therapeutic intervention could have positive benefits for older adults and warrants further study. 


\section{Age Inclusive CFT}

There is increasing evidence to suggest that older adults experience negative attitudes, stereotypes and behaviour including discrimination in many domains (McCann \& Giles, 2002). CFT theory suggests that due to our complex brains, such negative stereotypes and behaviour might lead to threat based "loops" between the highly evolved "new brain" which can plan, ruminate and problem-solve and the "old brain" which is threat-based, emotionally driven and has desires for status and social position (Gilbert, 2014). CFT proposes that such threat-based "loops" might be remediated through the emphasis of a common humanity which reduces the notion of "them and us". Consistent with this proposal, there is some evidence to suggest that intergenerational contact can help attenuate age-related stigma and subsequent ageist negative behaviour (Cummings et al. 2002). There is therefore a strong rationale for adopting an age inclusive approach towards delivering CFT, and it would be expected that the approach might serve to reduce any negative stereotypes towards older adults and increase people's ability to focus on similarities rather than differences.

\section{Aims}

The aim of this study was to evaluate and improve the effectiveness of an age inclusive compassionate minds (CM) group which is a trans-diagnostic group based on compassion-focused therapy (CFT). The CM group was originally developed for working age adults accessing secondary mental health services in Gloucestershire. Since 2015, the group has been piloted to include participants from both working age and older adult secondary mental health services in Gloucestershire.

The aims of this study were two-fold. Firstly, CFT is a relatively new therapeutic approach, and there is a need for further research to investigate the effectiveness of this therapy in improving psychological well-being. In particular, there is limited evidence for using this approach with an older adult population and within the context of an age inclusive group, so this study will make a contribution to this literature. Investigation of effectiveness was achieved through quantitative and qualitative methods, measuring the difference in pre and post group outcome measures and conducting interviews which included investigation into both group content and process. This exploration aimed to determine the most helpful and unhelpful aspects of the group which can then be used to modify future groups to increase their effectiveness.

Secondly, this study aimed to provide evidence to help determine if delivering age inclusive groups is a feasible and effective option. Significantly, there could be psychological benefits through having a diverse age range group through increasing understanding and awareness of others' difficulties who are at a different developmental stage, reducing negative attitudes people may have of different 
age groups. There are also likely to be practical implications to consider when delivering age inclusive groups. A detailed examination of the experiences of an age inclusive group was therefore undertaken to allow the service to consider if other therapeutic groups could benefit from a diverse age range and how best to implement these.

\section{Method}

\section{Study Design}

This study utilised a mixed method design combining qualitative interviews and quantitative self-report questionnaires as part of a routine service evaluation to understand the impact of the CM group. Full ethical approval was obtained from University of Bath Psychology Department Ethics Committee (Ethics: 17-217) and the Research \& Development Team of 2gether NHS Foundation Trust for Gloucestershire (Ref: 17/030/2gt/SE).

\section{Referral Pathway}

Participants were current service users of the working age or later life secondary mental health teams and were initially screened for their suitability for the CM group by their care coordinator. The care coordinator used their clinical judgement to determine whether the participant met the inclusion and exclusion criteria for the group and discussed the group with the potential participant, establishing informed consent to be referred for an initial assessment with the facilitators. Inclusion criteria consisted of meeting criteria for secondary mental health services; being willing and able to attend weekly group sessions lasting two hours; having long-standing struggles with self-criticism/self-blame; an ability/support to read and write and carry out between-session tasks; and finally, a readiness to engage with a programme requiring some level of self-directed practice. Exclusion criteria included having a significant cognitive impairment, having current psychosis and being substance dependent (where substance dependence was felt likely to adversely affect the ability to engage with the group content). The group facilitators then met individually with each potential participant to ensure their suitability for the group based on the inclusion and exclusion criteria and the facilitators' clinical judgement. Participants' diagnoses were not routinely recorded as part of the referral pathway for attending the group; however, participants attending the group typically experienced a range of different mental health problems of a level of severity and risk sufficient to warrant access to a secondary mental health service, including depression, anxiety bipolar disorder, complex trauma and psychosis. Informed consent to participate in the group was established verbally, and attendance of the group was deemed as confirmation of their continued consent to participate. 


\section{Structure and Content of the CM Group}

The age inclusive groups were facilitated by two experienced clinical psychologists who had attended training and were experienced in working within a CFT approach. Both received supervision from a clinical psychologist experienced in working with the CFT model. In common with previously published evaluations of CFT-based groups in routine clinical practice (e.g., McManus et al. 2018), the group programme was developed by the facilitators based on existing CFT group literature and published protocols (Gilbert, 2009, 2010; Lee and James, 2012; Welford, 2012).

Each group cohort had 6-10 members. The groups lasted for 20 sessions, mainly on a weekly basis but with occasional 1 or 2 week breaks in the programme due to practical reasons such as holidays. Each session lasted for two and a half hours with a coffee break. Each session followed a similar structure, starting with an experiential exercise such as soothing rhythm breathing, followed by psychoeducation and group discussion around the theme of that session. After the coffee break, the group carried out another experiential exercise followed by group reflection and discussion of their experiences of applying the CFT model. The session ended with participants and facilitators setting an intention to practice during the coming week and participants were provided with audio files or CDs of the facilitators providing guided mindfulness and imagery exercises to support their practice. The 20 sessions were organised according to themes as shown in Table 1, with key elements covered flexibly within each theme including interactive psychoeducation about CFT and compassionate mind training. This allowed the facilitators to respond to the individual needs of the group whilst maintaining an overall consistent approach across the different group cohorts. Halfway through the group programmes, each group member was invited to meet with a facilitator for $30 \mathrm{~min}$ to work on an individualised formulation. They were also invited to another 30-min individual session at the end of the group programme to review their overall experience of the group and plan any further input from the service.

\section{Quantitative Design}

The age inclusive group has been completed with four different cohorts with a total of 23 participants; 12 from working age services and 11 from later life services with an age range from 32 to 82 years old. Quantitative data was gathered from participants prior to commencement of the group during the final group session and at 3-month follow-up. This was routinely collected anonymised service data. The original aim was to also complete data at mid-group and follow-up, but due to lack of incomplete data this was not included. The facilitators administered the measures to the participants, and they were completed anonymously before the start of that group session. The quantitative measures were collated and analysed using descriptive and inferential statistics to evaluate the overall effectiveness of this group compared to the current literature for other CFT groups. 


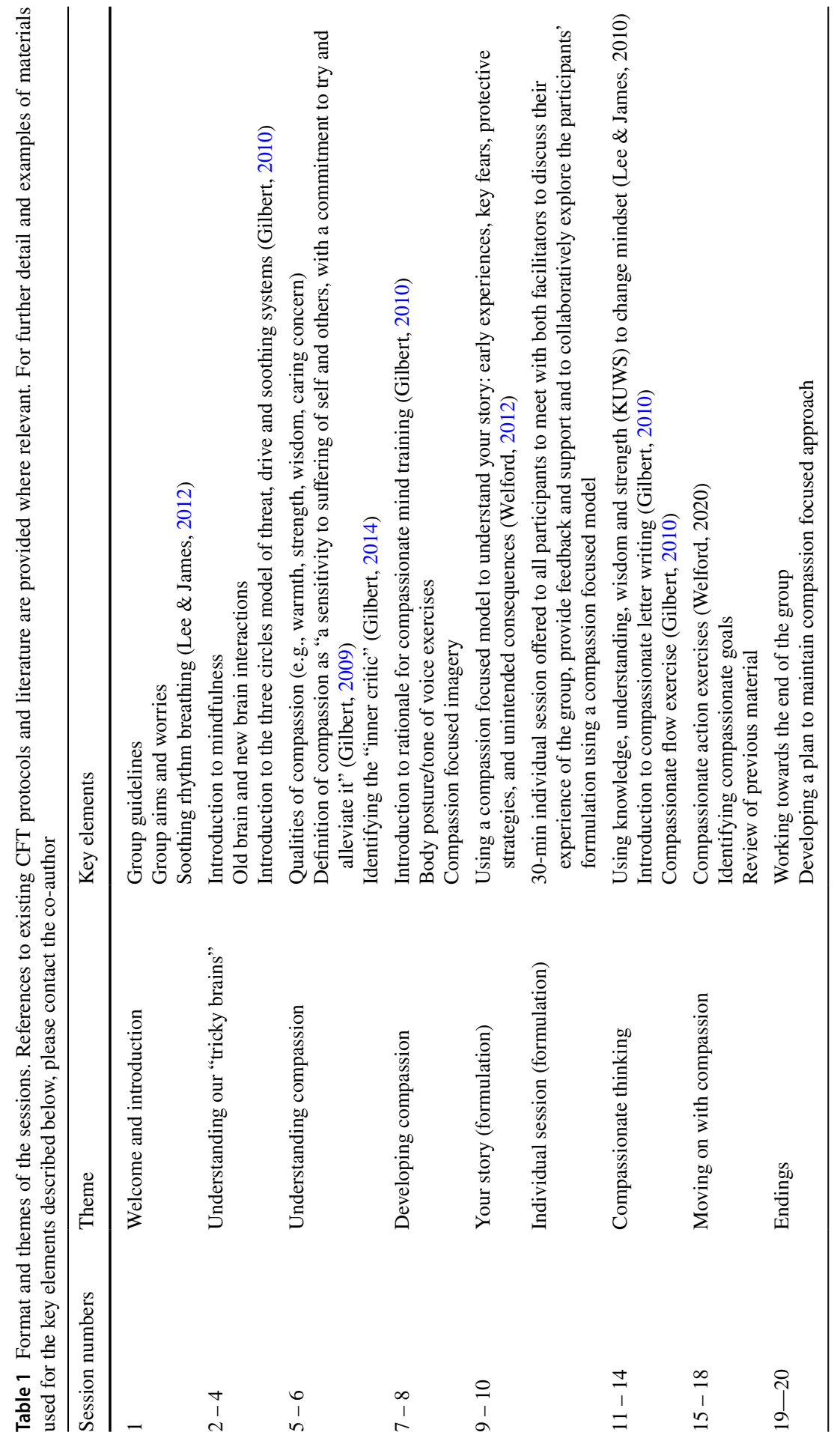




\section{Measures}

\section{The Self-Compassion Scale (Neff, 2003)}

This self-report scale has 26 items. The answering method is a Likert scale ranging from 1 (almost never) to 5 (almost always). This scale measures self-compassion and has demonstrated good psychometric properties including being a theoretically good measure of self-compassion with evidence of good test-retest reliability $(r=0.93)$ and validity (Neff, 2003). The scale has high internal consistency with a Cronbach's $\alpha=0.94$ (Neff et al. 2007). This scale has been implemented in an older adult population with high internal reliability (Allen et al, 2012).

\section{Mindful Attention Awareness Scale (Brown and Ryan, 2003)}

This self-report scale has 15 items. The answering method is a Likert scale ranging from 1 (almost always) to 6 (almost never). The scale assesses an awareness of what is occurring in the present which is a core characteristic of mindfulness. The scale has demonstrated good validity and reliability (Brown and Ryan, 2003). The scale has good internal reliability with a Cronbach's $\alpha=0.89$ (Mackillop and Anderson, 2007). This scale has also been used successfully in older adult populations (e.g., Raes et al. 2015).

\section{CORE-34 (Evans et al. 2002)}

This self-report scale has 34 items. The answering method is a Likert scale ranging from 0 (not at all) to 4 (most or all of the time). The scale examines domains of subjective well-being, symptoms, functioning and risk. The CORE-34 has demonstrated appropriate internal reliability with a Cronbach $\alpha$ between 0.75 and 0.95 , good validity and good sensitivity to change (Evans et al. 2002). The CORE has demonstrated good reliability in an older adult population when using the overall average; however, this reliability is reduced when examining specific domains (Barkham et al. 2005).

\section{Depression Anxiety and Stress Scale (Lovibond and Lovibond, 1995a, 1995b)}

This self-report scale has 42 items. The answering method is a Likert scale ranging from 0 (did not apply to me at all) to 3 (applied to me very much, or most of the time). The DASS examines depression, anxiety and stress and has been demonstrated to be a reliable and valid measure (Crawford and Henry, 2010). Internal consistency between the subscales is high, with Cronbach $\alpha=0.91$ for the depression subscale, 0.84 for anxiety subscale and 0.90 for the stress subscale (Lovibond and Lovibond, 1995a, 1995b). The DASS-21 has been investigated in older adults which 
found good internal consistency, excellent convergent validity and good discriminative validity (Gloster et al. 2008).

\section{Qualitative Design}

\section{Participants}

Participants were a convenience sample who gave informed consent to take part in the study after being invited at a CM follow-up group. Participants were five women and one man who had all completed a CM group, and they ranged in age from 34 to 69 years old. Five of the participants were from the same group cohort, and one participant was from a different group cohort. Three of the participants were considered in the working age range (18-64), and three were considered older adult (over 65 years old). Participants were all white British with English as their first language. All were in secondary mental health services and experienced a wide range of psychological difficulties.

\section{Interviews}

The interview questions were developed from existing feedback forms that participants completed on their final group session or shortly afterwards. These feedback forms asked questions on what people found helpful, unhelpful, the structure, length and age range of the group, experiences of being in a group and anything they would like changed. The researcher collaborated with the two group facilitators and a previous member of a CM group (who did not participate in the research) to discuss key areas of interest to the service that would be useful to explore further in individual interviews. This resulted in the following research questions for the qualitative component of the study being formulated:

1. What are participants' experiences of being in a mixed age range group?

2. What are the specific elements of the group that participants find most helpful and unhelpful?

3. What are participant's experiences of having an individual session to work on their formulation of their difficulties?

From these research questions, a semi-structured interview (see Appendix 1) was devised which incorporated specific questions and optional follow-up questions, whilst also allowing the researcher freedom to ask unplanned follow-up questions if they felt pertinent or relevant to the study's aims. The interviews typically lasted between 20 and $50 \mathrm{~min}$ and were audio recorded. The researcher was a clinical psychologist in training who had received teaching on qualitative research methods and was closely supervised by a researcher with experience in conducting 
qualitative research. The researcher did not know any of the participants personally or professionally.

\section{Procedure}

The researcher attended a follow-up group, and participants were informed about the project and given a participant information sheet. Those who were interested provided contact details and were contacted a week after receiving the participant information sheet to allow them time to reflect on participation. The interview took place at their local mental health clinic or in their own home, depending on preference. Written and verbal informed consent was obtained prior to commencing and participants were given a $£ 5$ voucher for taking part.

\section{Results}

\section{Quantitative Data Analysis}

Descriptive statistics (median and range) and statistical tests were generated using SPSS version 24. Due to the small sample size and the data violating the assumptions of normality, the non-parametric Wilcoxon signed-rank test was used to compare the pre and post data. Due to incomplete data, the questionnaires from the middle of the group and at 3-month follow-up were not included. The DASS was replaced with the CORE for the latter two group cohorts due to a change in service requirements in how routine data was collected.

The data analysis for the pre and post measures is depicted in Table 2. This analysis revealed a significant increase in the SCS and MASS and a significant decrease in the depression subscale within the DASS and risk subscale within the CORE. The overall score and other subscales within the CORE (wellbeing, symptoms and functioning) and DASS (anxiety and stress subscales) did not find any significant differences.

\section{Qualitative Data Analysis}

All interviews were audio recorded and transcribed verbatim. Thematic analysis was used to analyse the data using Braun and Clarke, 2006) approach. This consisted of firstly becoming familiar with the data through reading and re-reading the transcribed interviews. Secondly, the entire data set was coded, and then the codes collated with the relevant data extracts. Thirdly, the codes and collated data were examined to identify broad patterns of meaning in the data to identify potential themes. Fourthly, the themes were checked against the data set, and finally they were defined and named. An independent researcher coded a subset of the data and discussed their interpretation of the data with the primary researcher to help refine the final themes. The independent 
Table 2 Results of the analysis of the pre and post measures

\begin{tabular}{|c|c|c|c|c|c|}
\hline $\begin{array}{l}\text { Collation of } 4 \text { cohorts } \\
\text { available data sets }\end{array}$ & $\mathrm{N}$ & Pre & Post & $Z$ & $\begin{array}{l}\text { Wilcoxon } \\
\text { significance }(p)\end{array}$ \\
\hline $\begin{array}{l}\text { SCS: } \\
\text { Median } \\
\text { Range }\end{array}$ & 22 & $\begin{array}{l}2.00 \\
(1.31-3.48)\end{array}$ & $\begin{array}{l}2.71 \\
(1.12-3.29)\end{array}$ & -2.663 & .008 \\
\hline $\begin{array}{l}\text { MAAS: } \\
\text { Median } \\
\text { Range }\end{array}$ & 23 & $\begin{array}{l}3.4 \\
(2.13-4.38)\end{array}$ & $\begin{array}{l}3.93 \\
(2.33-5.27)\end{array}$ & -3.179 & .001 \\
\hline \multicolumn{6}{|l|}{ DASS: } \\
\hline $\begin{array}{l}\text { Depression } \\
\text { Median } \\
\text { Range }\end{array}$ & 12 & $\begin{array}{l}28.5 \\
(0-42)\end{array}$ & $\begin{array}{l}18.5 \\
(5-42)\end{array}$ & -2.280 & .023 \\
\hline $\begin{array}{l}\text { Anxiety } \\
\text { Median } \\
\text { Range }\end{array}$ & 12 & $\begin{array}{l}12.5 \\
(6-40)\end{array}$ & $\begin{array}{l}8.5 \\
(3-40)\end{array}$ & -1.156 & .248 \\
\hline $\begin{array}{l}\text { Stress } \\
\text { Median } \\
\text { Range }\end{array}$ & 12 & $\begin{array}{l}24 \\
(6-37)\end{array}$ & $\begin{array}{l}14.5 \\
(6-36)\end{array}$ & -1.808 & .071 \\
\hline $\begin{array}{l}\text { CORE - all items } \\
\text { Median } \\
\text { Range }\end{array}$ & 10 & $\begin{array}{l}1.64 \\
(1.15-2.68)\end{array}$ & $\begin{array}{l}1.22 \\
(0.76-2.59)\end{array}$ & -1.478 & .139 \\
\hline $\begin{array}{l}\text { CORE -Wellbeing } \\
\text { Median } \\
\text { Range }\end{array}$ & 10 & $\begin{array}{l}2.5 \\
(1.5-3.5)\end{array}$ & $\begin{array}{l}2 \\
(1-4)\end{array}$ & -1.404 & .160 \\
\hline $\begin{array}{l}\text { CORE — symptoms } \\
\text { Median } \\
\text { Range }\end{array}$ & 10 & $\begin{array}{l}2.33 \\
(1.33-3.25)\end{array}$ & $\begin{array}{l}1.67 \\
(1.08-3.92)\end{array}$ & -0.890 & .373 \\
\hline $\begin{array}{l}\text { CORE — functioning } \\
\text { Median } \\
\text { Range }\end{array}$ & 10 & $\begin{array}{l}1.63 \\
(1.25-1.75)\end{array}$ & $\begin{array}{l}1.38 \\
(0.75-2.33)\end{array}$ & -1.305 & .192 \\
\hline $\begin{array}{l}\text { CORE — risk } \\
\text { Median } \\
\text { Range }\end{array}$ & 10 & $\begin{array}{l}0.17 \\
(0.00-1.00)\end{array}$ & $\begin{array}{l}0.00 \\
(0.00-0.50)\end{array}$ & -2.020 & .043 \\
\hline
\end{tabular}

researcher was a clinical psychologist in training who had received training and experience in qualitative research methods.

The researcher approached the qualitative data from a critical realist perspective, which assumes that people's experiences and perspectives can be reflected through their language whilst recognising this is mediated both culturally and by the participant and researchers' interpretation of the events. The researcher had minimal experience or training of working in CFT. Four main themes were derived and are shown in Table 3. 
Table 3 Themes identified from participant interviews

\begin{tabular}{ll}
\hline Main themes & Sub-themes \\
\hline Connection with others & Cultivating empathy and compassion \\
& Shared solidarity in suffering \\
& Positive emotion towards the group \\
The experience of a diverse age & Fear of judgement \\
& Appreciation of a mixed age range group \\
Group as a secure space & Universality of distress \\
& Differing age-related needs \\
& Good structure \\
New strategies and tools & Supportive group \\
& Desire for continuation of group relationship \\
Activating soothing system & Awareness of emotions \\
& Ability to formulate difficulties \\
& Individuality of exercises \\
\hline
\end{tabular}

\section{Connection with Others}

A strong theme was that the group fostered an environment where people developed compassion and empathy for each other: "As time went on you got to know the group you also felt concern for each of the other people in the group" (P3; older adult).

"It was lovely being able to sort of empathise with people, more having heard of what they've been through, sort of like week by week" (P5; working age adult).

All participants reported experiencing positive emotions towards the group, and many discussed looking forward to attending each week: "I'd sort of wake up and think, oh great I got the group today will get to see all the people there, so I've very much enjoyed being in the group" (P6; older adult). Participants spoke fondly of having a shared sense of belonging through all having experienced psychological difficulties: "It was nice having other people around who I didn't feel, well you're okay and I'm not so I really shouldn't talk to you, cos you'll pick up on my not okayness. It was kinda like, well we're all kind of in this group together not being very ok with it all and trying very hard. So, I think the group was helpful in that" (P5; working age adult).

Many of the participants expressed initial concerns over how they presented themselves in the group. Some worried that others would think less of them through self-disclosure and feared showing vulnerability: "Don't want to throw your hat in the ring, you know" (P6; older adult). One participant was concerned they were too talkative, while another found it difficult to share with the group and feared their shyness would be viewed negatively: "I hope I wasn't a problem to other people" (P4; working age adult).

A key aspect of the group for some participants was learning not to take on others' problems which was something that they previously had struggled with: "So, 
the group really benefitted me in that way, I kind of learnt not to take on other people's problems really, so that was quite a big thing for me" (P4; working age adult).

Learning to reconnect with people and develop interpersonal skills appeared to be key for a couple of participants: "The group is good to try to interact with others, I think that's part of what goes wrong with people their own ability to connect it comes down to that a lot, so yeah" (P5; working age adult).

\section{The Impact of Diverse Ages}

All participants spoke positively of appreciating the differing age range of the group members: "It was a just nice size group and the diversity of people and the age, that's always good" (P2; working age adult).

Having a range of ages helped participants recognise that psychological distress can happen to anyone at any point in their life: "Everybody in some stage of their life, whether you be younger, middle age, older, people have problems, people have mental health problems" (P2; working age adult). "Definitely yes everyone was nice, and it helped me to sort of see that you know that it can affect anyone at any age and I think it's just good to have a good mix of people really" (P4; working age adult). This appeared to be quite powerful in both age groups where they recognised the plight that different generations face: "Yes, what some younger people are carrying, which I know I had to carry and thankfully they are getting help again" (P6; older adult).

One of the older adults reported difficulty hearing the group members and facilitators and would have benefitted from people speaking louder. A working age participant felt that hearing was a difficulty for the older adults in the group: "Those who were a bit older...they couldn't necessarily hear me very well...I think everybody needed to speak up for the benefit of everybody else kinda thing" (P4; working age adult).

One older adult reported that they did not approve of people swearing and would have appreciated group rules over this. "I find it offensive" (P6; older adult).

Two of the working age participants felt that some of the older adults required further time to consolidate the learning from the group and had difficulty recalling as much from previous sessions compared with younger people in the group: "My perception was maybe the people were a bit older, I don't know how to say this without being rude, maybe they needed a bit more time for the therapy, a couple of them, for the therapy to work" (P4; working age adult).

\section{Group as a Secure Space}

A strong theme was that the group fostered an environment which was supportive, containing and structured: "I think when you are going through and you are going through things in life, I did feel supportive it was a nice little safety net, I could go there for a couple of hours and I'd be alright" (P2; working age adult). "We are all there to be helped and we helped each other we were a supportive group, we kind of 
supported each other which is always good. Yeah, it was a nice group" (P4; working age adult).

The majority of the participants spoke highly of the structure of the group where the facilitators were mindful of the needs of the group, with a good mix of learning and discussion: "It was structured, although you didn't know it was being structured in that way, it was good how they did it, the two of them complimented each other and um yeah it worked well" (P2; working age adult).

Most of the members reported they would have valued more follow-up sessions. Some felt this would help formulate their difficulties better: "I know money, time, this that and the other but it probably been nice to have a couple of sessions as a refresher, so you can put it all into context" (P2; working age adult).

Others felt it would have helped with sharing of resources and continued learning: "I think further groups with someone not, you know, someone knowledgeable leading the group, would take people, you know, further on their path really" (P3; older adult).

Many of the group members would have preferred the group to increase the spacing of latter sessions to avoid an abrupt finish: "You got quite attached" (P3; older adult). "Maybe do twenty weeks and then leave it for a month and have a few more meetings perhaps even five or ten so you didn't suddenly feel so abandoned" (P1; older adult).

\section{New Strategies, Concepts and Tools}

The majority of participants discussed enjoying creating an imagery of a safe and happy space. Almost all participants emphasised how helpful the soothing rhythm breathing had been: "The breathing is really quite useful. I mean it doesn't cure anything; it's not a wonder cure, but it definitely helped" (P1; older adult).

Participants in the group discussed an enlightened understanding of emotions.

"I suppose the biggest thing is that nothing really lasts forever. You know you might feel absolutely down in the dumps one day, or angry or felt rejected, or any negative emotion but it won't last forever" (P1; older adult). "I'm much more aware of my, prior to this mood, the word mood didn't evoke any understanding and some intellectual understanding of it but nothing in my body, emotional yea? Now mood and feelings resonate in me" (P3; older adult).

Though participants found most of the content helpful, there was individual variation where some people disliked certain exercises and one individual found an exercise emotionally difficult: "I'd find my mind drifting in that because I felt like damned and cursed so no one's peaceful well-wishing would even touch that" (P5; working age adult).

Through having an individual session, some of the participants reported being able to understand the theory in context of their own lives: "That was useful because it allowed me to place what's happened to me and to build up some goals for the future" (P4; working age adult). Some felt that longer and additional individual sessions would allow them to build on this further. 


\section{Discussion}

This study aimed to evaluate the effectiveness of a mixed age range CFT group in secondary mental health services in order to propose improvements. The overall results suggest that this was a beneficial group that had a positive impact on participants. The quantitative results demonstrate significant increases in selfcompassion and mindfulness attention awareness; however, most of the domains within the mental health measures (DASS \& CORE) did not reach significance, though all domains showed a reduction in symptoms. The lack of significant change on the majority of CORE domains and anxiety and stress components of the DASS domains is dissimilar to some of the CFT group literature where significant positive changes on mental health measures were achieved (e.g., Judge et al., 2012; Lucre and Corten, 2013). A probable explanation and limitation that as the DASS was replaced with the CORE, these questionnaires had roughly half the sample size in comparison with the SCS and MAAS which could have contributed to the lack of statistical significance due to reduced power. Nonetheless, this study provides important preliminary evidence and offers useful insight into future research, such as reducing frequency of data collected to hopefully improve completion rates by minimising the burden on staff and participants.

Despite the consistent lack of statistical change on the mental health measures, the qualitative results suggest that the group had a powerful impact on its members. A crucial aspect of the experience of the group was connection with others. This is highly important as creating a group context which cultivates compassion and empathy towards its members enables individuals to feel reduced shame, increased validation and to feel soothed (Bates, 2005). Participants described the group as a positive experience which they would look forward to attending each week. CFT focuses on the importance of engaging in experiences which will help activate the affiliative/soothing system and attending a group which experiences such positive cohesiveness will activate this system. Participants also expressed a sense of belonging through sharing difficulties; the CM group allowed the opportunity for affiliative sharing where people share their own stories and listen to others which results in the normalisation of their suffering. This in turn helps people feel less alone and increases connectedness with others resulting in reduced feelings of shame (Bates, 2005). The importance of this group connection is consistent with Craig et al.'s (2020) review, which found that CFT is especially effective in a group format over $12 \mathrm{~h}$.

Significantly, results from the qualitative analysis demonstrated that the experience of being in a mixed age range was positively appreciated by all group members and contributed to people's ability to recognise the ubiquitous nature of psychological distress. This is significant as a key aspect of CFT is promoting the idea of a common humanity to reduce the idea of "them and us". This may have been particularly important for older adults where due to cohort beliefs may have felt increased stigma and alienation at experiencing mental health difficulties (Palinkas et al. 2007). Previous research has found that intergenerational contact reduces ageist stigma (Cummings et al. 2002), and it could be speculated that the 
sub-themes derived in this study including "the universality of distress", "shared solidarity in suffering" and "cultivating empathy and compassion" suggest some mechanisms that may play an important role in this. Further exploration of the role of these themes within intergenerational contexts is a possible direction for future research.

Participants valued the experience of learning new strategies and tools to activate their soothing system and relate to their difficulties differently. There was a high desire for continuation of the group experience with the focus on increased learning of strategies and ways of continuing implementing them into people's lifestyles. It is possible that increased learning and integration of these activities into people's lifestyles through additional follow-up groups could lead to further positive benefits on their psychological well-being.

\section{Recommendations}

Based on these findings, the following recommendations were made for the service.

\section{Mixed-Age Range Recommendations}

Ensure that all participants can hear the facilitators and group members. This could be achieved by enquiring about hearing difficulties in the initial referral assessment. Practical strategies to attenuate this could be asking everyone to speak louder and people with hearing loss to sit closer to the facilitators during group exercises. Consider cohort beliefs when creating group rules, for example, recognising that some people, possibly older adults more so, may not be comfortable with swearing, so setting up rules to ensure all participants feel comfortable with the group language.

Recognising that cognitive capabilities will vary amongst age and being mindful to pitch the theoretical teaching at a level suitable for all ages and a range of abilities. Making use of memory aids to improve recall of material learnt, for example, simplified summaries of each session. Being aware that due to cohort beliefs, working age participants may be wary of disclosing information that they may deem upsetting for older adults to hear due to the perception that they will be less familiar with such issues, for example, issues around self-harm.

\section{Individual Formulation Session Recommendations}

Consider increasing the number of individual formulation sessions to further consolidate people's ability to place the learning in context. Having reminders of the group content during the formulation session to aid people's memories of the sessions. Consider having a longer amount of time dedicated to this session. Consider providing handouts of the outcome of the formulation session to aid participants' memory and understanding. 


\section{Content Recommendations}

Be aware of the individuality of participants and how some exercises may provoke a strong negative reaction, so having the option of another practice to do during this time may be helpful. The pragmatic exercises were powerful and fondly remembered, such as going on an outing together. Provide advice to help people continue with the exercises once the group has finished.

\section{Follow-Up Group Recommendations}

To reduce the sense of loss and sadness when the group ends, it may be helpful to gradually increase the time between the last few sessions. An increased amount of follow-up sessions may be helpful for improving adherence to the model and allowing participants to place it successfully into context. Guidance on further resources and groups in the community would help with continuation of psychological learning and connecting with others.

\section{Evaluation Recommendations}

Collecting frequent mental health measures can be time-consuming and arduous for both clients and staff, which may explain the lack of complete data for the mid-group and 3-month follow-up. Focusing instead on collecting 3-month follow-up data rather than mid-group data may help minimise the burden whilst gaining valuable data on the sustained effectiveness of the group.

\section{Service Recommendations}

Mixed-age range groups have been well-received with all members interviewed appreciating the diverse age range. Consider having equity of access across other psychological therapy groups in the trust.

\section{Feedback and Dissemination}

The results and recommendations of this study were fed back to the older adult service lead. In response, several recommendations were implemented. Firstly, an extra "follow-up" session was included to allow a more gradual ending of the group. Secondly, a group of experts by experience began working with the service's social inclusion team on developing a community-based group for "graduates" of the CM group, aiming to allow people to continue their compassion focused skills on completion of the group. Thirdly, a review was planned to consider different measures to evaluate the group to capture the qualitative findings more effectively. Finally, the findings were to be discussed with other service 
managers to consider how age inclusive groups could be considered more widely in the trust.

\section{Limitations}

The small number of participants overall and the convenience sample for the qualitative interviews means it is difficult to generalise the results to other groups or settings. Further, five of the participants for the qualitative interviews were from one cohort, whereas one participant was from a different cohort (P1). Each cohort undergoes a unique group relationship, so ideally having all participants from one cohort would have been desired. However, having a participant from a different cohort who also had similar positive group experiences can also be viewed as a strength as it shows some generalisability.

In retrospect, due to the study design as a routine service evaluation, there is missing data which limits the conclusions which can be drawn. It is therefore recommended that future evaluations of similar group interventions collect additional anonymised data relating to the demographic characteristic of the group participants such as gender, ethnicity, mental health diagnosis and other treatments received. Due to missing data, it was also not possible to include participants' questionnaire scores during mid-group and at 3-month follow-up group which would have strengthened the study. In addition, it was not possible to calculate the internal consistency of the measures used due to the way in which these measures were collected and it is recommended this is addressed in future studies to improve the rigour of the evaluation. A further limitation was the lack of control group which would have provided stronger evidence that the improvements found were due to the CFT intervention.

In conclusion, this study aimed to evaluate a mixed age range CFT group for participants in secondary mental health care. The results provide preliminary evidence that the group is well received and has a beneficial impact on participants. The CFT group appeared to have a significant impact on participants' group experience of compassionately and positively connecting with others whilst learning strategies and skills to help them relate to their difficult experiences differently. Having a diverse range of ages appeared to enhance participants' understanding on the ubiquity of psychological distress, helping normalise their own difficult experiences, thus resulting in increased self-compassion. These results also suggest that awareness of differing age-related needs is important for diverse age range groups to function at an optimal level. Further research adopting these mixed age range recommendations and further examining the utility of diverse age range groups is required.

Appendix 1 -Interview schedule

\section{Research question "What are the specific elements of the group that partici- pants find most helpful and unhelpful?".}

Question 1.

Have you noticed any changes in your well-being as a result of attending this group?

Question 2. 
Were there any particular exercises that you learnt from attending the group that you have incorporated into your life?

Optional follow-up questions:

a) What were the most helpful exercises from attending the group?

b) What were the least helpful exercises from attending the group?

c) Is there any part of the content that you think should be changed for future groups?

\section{Question 3.}

What was your experience of being in a group?

Optional follow-up question:

a) What was it like listening to others experiences and sharing your own experiences in a group setting?

b) Was there anything helpful about being in a group?

c) Was there anything unhelpful about being in a group?

Question 4.

Is there anything that could have been done differently to improve the experience of being in a group?

Research question "What are participants' experiences of being in a mixed age range group?'.

Question 5.

What was your experience of being in a mixed age range group?

Question 6.

Were there any positives of being in a mixed age range group?

Question 7.

Were there any negatives of being in a mixed age range group?

Optional follow-up questions:

a) Do you feel you learnt anything extra by being in a mixed age range group?

b) Do you feel you would have learnt more if you were in a similar range group?

Research Question: What are participant's experiences of having an individual session to work on their formulation of their difficulties?

Question 8.

What was your experience of having an individual session to help formulate your difficulties?

Question 9.

What was your understanding of this session?

Question 10.

Is there anything you would have liked to have been done differently in this session?

Optional follow-up questions:

a) Was there anything helpful about this session?

b) Was there anything unhelpful about this session?

\section{Declarations}

Conflict of Interest The authors declare no competing interests. 
Open Access This article is licensed under a Creative Commons Attribution 4.0 International License, which permits use, sharing, adaptation, distribution and reproduction in any medium or format, as long as you give appropriate credit to the original author(s) and the source, provide a link to the Creative Commons licence, and indicate if changes were made. The images or other third party material in this article are included in the article's Creative Commons licence, unless indicated otherwise in a credit line to the material. If material is not included in the article's Creative Commons licence and your intended use is not permitted by statutory regulation or exceeds the permitted use, you will need to obtain permission directly from the copyright holder. To view a copy of this licence, visit http://creativecommons.org/licen ses/by/4.0/.

\section{References}

Allen, A. B., Goldwasser, E. R., \& Leary, M. R. (2012). Self-compassion and well-being among older adults. Self-Identity, 11(4), 428-453. https://doi.org/10.1080/15298868.2011.595082

Ashworth, F., Clarke, A., Jones, L., et al. (2015). An exploration of compassion focused therapy following acquired brain injury. Psychological and Psychotherapy: Theory, Research and Practice, 88(2), 143-162. https://doi.org/10.1111/papt.12037

Barkham, M., Culverwall, A., Spindler, K., \& Twigg, E. (2005). The CORE-OM in an older adult population: Psychometric status, acceptability, and feasibility. Aging Mental Health, 9(3), 235245. https://doi.org/10.1080/13607860500090052

Bartels-Velthuis, A. A., Schroevers, M. J., van der Ploeg, K., Koster, F., Fleer, J., \& van den Brink, E. (2016). A mindfulness-based compassionate living training in a heterogeneous sample of psychiatric outpatients: A feasibility study. Mindfulness, 7, 809-818. https://doi.org/10.1007/ s12671-016-0518-8

Bates, T. (2005). The expression of compassion in group psychotherapy. In P. Gilbert (Ed.), Compassion: Conceptualisations, research and use in psychotherapy (pp. 369-386). Routledge.

Braehler, C., Gumley, A., Harper, J., Wallace, S., Norrie, J., \& Gilbert, P. (2013). Exploring change processes in compassion focused therapy in psychosis: Results of a feasibility randomized controlled trial. British Journal of Clinical Psychology, 52, 199-214. https://doi.org/10.1111/bjc. 12009

Braun, V., \& Clarke, V. (2006). Using thematic analysis in psychology. Qualitative Research in Psychology, 3(2), 77-101. https://doi.org/10.1191/1478088706qp063oa

Brown, K. W., \& Ryan, R. M. (2003). The benefits of being present: Mindfulness and its role in psychological well-being. Journal of Personality and Social Psychology, 84(4), 822-848. https:// doi.org/10.1037/0022-3514.84.4.822

Clapton, N. E., Williams, J., Griffith, G. M., \& Jones, R. S. (2018). 'Finding the person you really are ... on the inside': Compassion focused therapy for adults with intellectual disabilities. Journal of Intellectual Disabilities, 22(2), 135-153. https://doi.org/10.1177/1744629516688581

Collins, R. N., Gilligan, L. J., \& Poz, R. (2018). The evaluation of a compassion-focused therapy group for couples experiencing a dementia diagnosis. Clinical Gerontologist, 41(5), 474-486. https://doi.org/10.1080/07317115.2017.1397830

Craig, C., Hiskey, S., \& Spector, A. (2020). Compassion focused therapy: A systematic review of its effectiveness and acceptability in clinical populations. Expert Review of Neurotherapeutics, 20(4), 385-400. https://doi.org/10.1080/14737175.2020.1746184

Crawford, J. R., \& Henry, J. D. (2010). The depression anxiety stress scales (DASS): Normative data and latent structure in a large non-clinical sample. British Journal of Clinical Psychology, 42(2), 111-131. https://doi.org/10.1348/014466503321903544

Crocker, J., \& Canevello, A. (2012). Consequences of self-image and compassionate goals. In P. G. Devine \& A. Plant (Eds.), Advances in experimental social psychology (pp. 229-277). Elsevier.

Cummings, S. M., Williams, M. M., Ellis, R., \& A. (2002). Impact of an intergenerational program on 4th graders' attitudes toward elders and school behaviours. Journal of Human Behaviour in the Social Environment, 6(3), 91-107. https://doi.org/10.1300/J137v08n01_03

Duarte, C., \& Pinto-Gouveia, J. (2017). Compassionate attention and regulation of eating behaviour: A pilot study of a brief low-intensity intervention for binge eating. Clinical Psychology \& Psychotherapy, 24(3), 1437-1447. https://doi.org/10.1002/cpp.2094. 
Evans, C., Connell, J., Barkham, M., Margison, F., McGath, G., Mellor-Clark, J., \& Audin, K. (2002). Towards a standardised brief outcome measure: Psychometric properties and utility of the CORE-OM. The British Journal of Psychiatry, 180(1), 51-60. https://doi.org/10.1192/bjp.180.1. 51

Feliu-Soler, A., Pascual, J. C., Borràs, X., Portella, M. J., Martín-Blanco, A., Armario, A., Alvarez, E., Pérez, V., \& Soler, J. (2014). Effects of dialectical behaviour therapy-mindfulness training on emotional reactivity in borderline personality disorder: Preliminary results. Clinical Psychology and Psychotherapy, 21(4), 363-370. https://doi.org/10.1002/cpp.1837

Gilbert, P. (2009). The compassionate mind: A new approach to life's challenges. Constable-Robinson.

Gilbert, P. (2014). The origins and nature of compassion focused therapy. British Journal of Clinical Psychology, 53, 6-41. https://doi.org/10.1111/bjc.12043

Gilbert, P. (2018). Introducing compassion focused therapy. Advances in Psychiatric Treatment, 15, 199-208. https://doi.org/10.1192/apt.bp.107.005264

Gilbert, P. \& Irons, C. (2005). Therapies for shame and self-attacking, using cognitive, behavioural, emotional imagery, and compassionate mind training. In P. Gilbert (Ed.) Compassion: Conceptualisations research and use in psychotherapy. London: Brunner-Routledge.

Gilbert, P. (2010). Training our minds in, with and for compassion: An introduction to concepts and compassion-focused exercises. Retrieved from http://wtm.thebreathproject.org/wp-content/uploa ds/2016/03/COMPASSION-HANDOUT.pdf

Gloster, A. T., Rhoades, H. M., Novy, D., Klotsche, J., Senior, A., Kunik, M., Wilson, N., \& Stanley, M. A. (2008). Psychometric properties of the depression anxiety and stress scale-21 in older primary care patients. Journal of Affective Disorders, 110(3), 248-259. https://doi.org/10.1016/j. jad.2008.01.023

Judge, L., Cleghorn, A., McEwan, K., \& Gilbert, P. (2012). An exploration of group-based compassion focused therapy for a heterogeneous range of clients presenting to a community mental health team. International Journal of Cognitive Therapy, 5(4), 420-429. https://doi.org/10.1521/ ijct.2012.5.4.420

Kirby, J. N., Tellegen, C. L., \& Steindl, S. R. (2017). A meta-analysis of compassion-based interventions: Current state of knowledge and future directions. Behaviour Therapy, 48(6), 778-792. https://doi.org/10.1016/j.beth.2017.06.003

Lee, D. \& James, S. (2012). The compassionate mind approach to recovering from trauma. London, UK: Robinson

Lovibond, P. F., \& Lovibond, S. H. (1995a). The structure of negative emotional states: Comparison of the depression anxiety stress scales (DASS) with the Beck depression and anxiety inventories. Behaviour Research Therapy, 33(3), 335-343. https://doi.org/10.1016/0005-7967(94)00075-U

Lovibond, S. H., \& Lovibond, P. F. (1995b). Manual for the depression anxiety stress scales (2nd ed.). Psychology Foundation.

Lucre, K. M., \& Corten, N. (2013). An exploration of group compassion-focused therapy for personality disorder. Psychology and Psychotherapy, 86(4), 387-440. https://doi.org/10.1111/j.20448341.2012.02068.x

MacBeth, A., \& Gumley, A. (2012). Exploring compassion: A meta-analysis of the association between self-compassion \& psychopathology. Clinical Psychology Review, 32(6), 545-552. https://doi.org/10.1016/j.cpr.2012.06.003

MacKillop, J., \& Anderson, E. J. (2007). Further psychometric validation of the mindful attention awareness scale (MAAS). Journal of Psychopathology and Behavioural Assessment, 29, 289293. https://doi.org/10.1007/s10862-007-9045-1

McCann, R., \& Giles, H. (2002). Ageism in the workplace: A communication perspective. In T. D. Nelson (Ed.), Ageism: Stereotyping and prejudice against older persons (pp. 163-199). The MIT Press.

McManus, J., Tsivos, Z., Woodward, S., Fraser, J., \& Hartwell, R. (2018). Compassion focused therapy groups: Evidence from routine clinical practice. Behaviour Change, 35(3), 167-173. https:// doi.org/10.1017/bec. 2018.16

Mirowsky, J., \& Ross, C.E. (1992). Age and depression. Journal of Health and Social Behaviour, 33(3), 187-205. https://psycnet.apa.org/doi/https://doi.org/10.2307/2137349

Neff, K. D. (2003). Development and validation of a scale to measure self-compassion. Self and Identity, 2(3), 223-250. https://doi.org/10.1080/15298860309027 
Neff, K. D., Rude, S. S., \& Kirkpatrick, K. L. (2007). An examination of self-compassion in relation to positive psychological functioning and personality traits. Journal of Research in Personality, 41(4), 908-916. https://doi.org/10.1016/j.jrp.2006.08.002

Noorbala, F., Borjali, A., Ahmadian-Attari, M. M., \& Noorbala, A. A. (2013). Effectiveness of compassionate mind training on depression, anxiety, and self-criticism in a group of Iranian depressed patients. Iranian Journal of Psychiatry, 8(3), 113-117.

Palinkas, L. A., Criado, V., Fuentes, D., Shepherd, S., Milian, H., Folson, D., \& Jeste, D. V. (2007). Unmet needs for services for older adults with mental illness: Comparison of views of different stakeholder groups. The American Journal of Geriatric Psychiatry, 15(6), 530-540. https://doi. org/10.1097/JGP.0b013e3180381505

Phillips, W. J., \& Ferguson, S. J. (2012). Self-compassion: A resource for positive aging. The Journals of Gerontology: Series B, 68(4), 529-539. https://doi.org/10.1093/geronb/gbs091

Raes, A. K., Bruyneel, L., Loeys, T., Moerkerke, B., \& De Raedt, R. (2015). Mindful attention and awareness mediate the association between age and negative affect. The Journals of Gerontology: Series B, 70(2), 179-188. https://doi.org/10.1093/geronb/gbt074

Rockliff, H., Gilbert, P., McEwan, K., Lightman, S., \& Glover, D. (2008). A pilot exploration of heart rate variability and salivary cortisol responses to compassion-focused imagery. Journal of Clinical Neuropsychiatry, 5, 132-139.

Welford, M. (2012). The compassionate mind approach to building your self-confidence using compassion focused therapy. London, UK: Robinson.

Publisher's Note Springer Nature remains neutral with regard to jurisdictional claims in published maps and institutional affiliations. 